
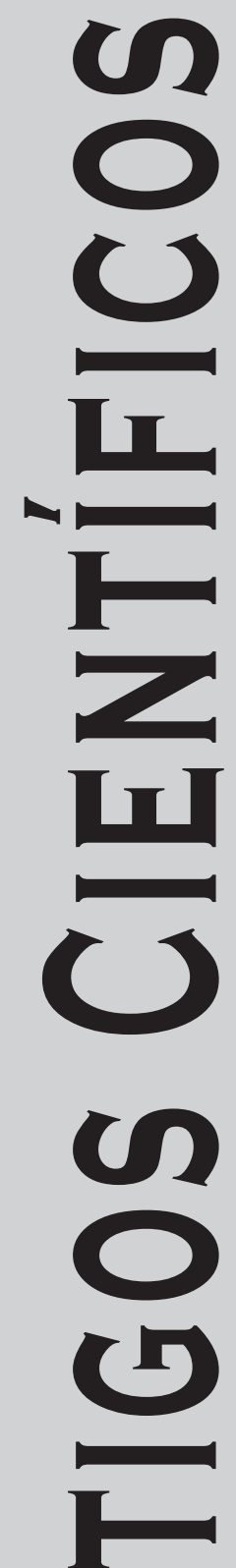
ac

Revista Música Hodie, Goiânia - V.14, 238p., n.1, 2014 


\title{
Estudo e Performance de Processos Rítmicos do Século XX com Auxílio de Dispositivos Eletrônicos
}

\author{
Cesar Adriano Traldi (Universidade Federal de Uberlândia, Uberlândia, MG) \\ ctraldi@gmail.com
}

\begin{abstract}
Resumo: Esse texto apresenta pesquisa desenvolvida na Universidade Federal de Uberlândia, onde processos rítmicos criados e/ou desenvolvidos no século XX estão sendo estudados com o auxílio de dispositivos eletrônicos. Alguns desses processos rítmicos são descritos, em seguida, apresentamos experiências realizadas com modulação métrica e phase-shifting e finalizamos refletindo que a utilização de dispositivos eletrônicos é uma importante ferramenta no processo de estudo e performance desses procedimentos, assim como para a realização de performances musicais interativas com exploração de processos rítmicos.

Palavras-chave: Estruturas rítmicas; Dispositivos eletrônicos e performance musical; Modulação métrica e phase-shifting.
\end{abstract}

Study and Performance of Rhythmic Processes of the Twentieth Century With the Help of Electronic Devices

Abstract: This paper presents research carried in Uberlândia Federal University where rhythmic processes created and/or developed in the twentieth century are being studied with the aid of electronic devices. Some of these rhythmic processes are described, while some experiments are presented with metric modulation and phase-shifting and we finalize reflecting that the use of electronic devices is an important tool in the study and performance of these procedures as well as for the realization of interactive musical performances with exploration of rhythmic processes. Keywords: Rhythmic structures; Electronic devices and musical performance; Metric modulation and phase-shifting.

\section{Introdução}

Entre as inúmeras inovações surgidas na produção musical durante o século XX está a criação e o desenvolvimento de novos processos rítmicos. Apesar de o aspecto rítmico estar presente nas composições dos diferentes períodos da música, ele normalmente foi utilizado como um elemento de menor importância que servia apenas para dar movimento temporal para a harmonia e melodia. Prova disso são as tradicionais disciplinas de análise musical, presentes na maioria dos cursos de música, que raramente estudam ou destacam os aspectos rítmicos utilizados pelos compositores em suas composições.

Entretanto, a busca dos compositores do século XX por novas sonoridades e procedimentos composicionais fez surgir novos e inovadores procedimentos rítmicos que colocaram esse aspecto musical no mesmo patamar de importância de harmonia e melodia e muitas vezes como principal elemento composicional de uma obra. Assim, o estudo e compreensão desses processos são de extrema importância na formação de intérpretes, compositores, educadores e pesquisadores musicais do século XXI.

Outro importante elemento utilizado na produção e performance musical do século XX e XXI é a utilização de dispositivos eletrônicos, com destaque aos computadores portáteis pessoais. Essa ferramenta multiuso tem estado cada dia mais presente nas diferentes atividades do ser humano, auxiliando e ampliando as possibilidades de comunicação, criação, interatividade, diversão, etc.

Esse texto apresenta o trabalho de pesquisa desenvolvido na Universidade Federal de Uberlândia, com financiamento da Fundação de Amparo à Pesquisa do Estado de Minas Gerais - FAPEMIG, onde procedimentos rítmicos criados e/ou desenvolvidos no século XX estão sendo estudados e realizados com o auxílio de dispositivos eletrônicos. A análise de processos rítmicos com o auxílio de dispositivos eletrônicos tem se demonstrado como uma 
importante ferramenta para compreensão e auxílio na realização de diferentes aspectos musicais por intérpretes. Além disso, a ampliação desses aspectos através da realização desses procedimentos rítmicos com a utilização de dispositivos eletrônicos faz surgir novas possibilidades sonoras e composicionais e, assim, a criação de um novo repertório musical.

Iniciamos apresentando alguns dos procedimentos rítmicos do século XX que foram criados e/ou desenvolvidos nesse período e que possuem grande importância nas composições que os utilizam. Em seguida, apresentaremos algumas das experiências já desenvolvidas onde foram realizados um Estudo e Performance de modulações métricas com o auxílio do computador e o software Pure Data e, em seguida, o estudo do processo de phase-shifting por meio de uma programação realizada também com software Pure Data e a composição de uma obra interativa onde o processo de phase-shifting é realizado por um intérprete humano e o computador. Finalizamos apresentando reflexões e conclusões que demonstram que a utilização de dispositivos eletrônicos é uma importante ferramenta no estudo de aspectos musicais complexos, além de um amplo instrumento para a realização de performances e composições musicais.

\section{Procedimentos Rítmicos do Século XX}

O século XX é marcado por inúmeras inovações na composição musical e, entre elas, o desenvolvimento de novos e inovadores procedimentos rítmicos que auxiliou no surgimento de novas e complexas sonoridades.

Em 1965, o compositor norte americano Steve Reich criou acidentalmente o processo de phase-shifting (mudança de fase). O compositor estava realizando experimentos de loop em uníssono entre dois fragmentos de gravações de frases vocais tocadas simultaneamente em gravadores idênticos e percebeu que, apesar disso, existia uma pequena variação de velocidade entre eles. Assim, lentamente ocorria um deslocamento entre as duas reproduções. Reich se interessou pelas novas sonoridades que surgiram do gradual deslocamento entre as duas reproduções e resolveu explorar esse procedimento em suas obras musicais.

As primeiras composições de Steve Reich com a utilização de phase-shifting foram as obras acusmáticas It's Gonna Rain (1965) e Come out (1966).

Segundo Steve Reich (1981), a composição musical parte literalmente da exploração detalhada dos processos utilizados. Assim, seu maior interesse é "perceber os processos" e “ouvir os processos acontecendo” (REICH, 1981). Segundo Lesage:

...a impessoalidade e objetividade no processo são metas perseguidas por Reich. A busca do compositor é a de uma escuta ateleológica (não direcional, desprovida de fim), inacessível ao discurso racional. A própria experiência musical de Reich tem seu interesse oriundo na impessoalidade: 'O prazer que eu tenho ao tocar não é o prazer de me expressar, mas de subjugar-me a música e experienciar o êxtase advindo de ser parte dela'. (LESAGE, 2011)

Nas composições com phase-shifting, o processo rítmico utilizado é o principal elemento musical da obra. Ou seja, o procedimento rítmico torna-se elemento fundamental do discurso musical.

não há segredos estruturais na música de Reich que ele conheça e que não se ouçam, ou seja, estrutura e conteúdo musical são idênticos. Daí explica-se também a dificuldade da análise nas obras da primeira fase de Reich: Uma vez explícitos todos os procedimentos, não há segredos composicionais, e a análise se dá como simples descrição. (LESAGE, 2011) 
Em 1967, Steve Reich compõe suas primeiras obras para instrumentos acústicos utilizando o processo de phase-shifting. A primeira composição foi Piano Phase e, no mesmo ano, Violin Phase. Piano Phase foi composta para dois pianos (ou duas marimbas, o compositor coloca essa possibilidade na partitura). A obra é composta por três frases musicais diferentes e o processo de phase-shifting é realizado nas três. Os dois intérpretes tocam em uníssono as frases musicais e

A mudança de fase (phase-shifting) é realizada nessa obra através de um processo em que um dos intérpretes torna seu pulso ligeiramente mais rápido, fazendo com que dois pulsos diferentes coexistam durante determinado tempo. (CAMPOS, TRALDI e MANZOLLI, 2011)

Violin Phase foi composta para quatro intérpretes. O procedimento para a realização das mudanças de fase é semelhante ao utilizado na obra Piano Phase, tendo a sonoridade expandida através da utilização de um número maior de instrumentos.

Em 1970/71, Reich compõe a obra Drumming para quatro pares de bongôs, três glockenspiels, três marimbas e duas vozes femininas. Em alguns momentos da peça, os instrumentistas também utilizavam o assobio como recurso instrumental. Nessa obra, Reich "Consagra o procedimento rítmico que chamamos de defasagem, utilizado em seus primeiros trabalhos” (FRIDMAN, 2012). Ele realiza o procedimento rítmico através da substituição de pausas por notas ou notas por pausas.

Drumming foi composta logo após um curto período em que o compositor passou em Gana, África, estudando a percussão africana, incluindo o ritmo conhecido por Gahu, característico da tribo Ewe, que foi uma das inspirações de Reich para compor a peça. (FRIDMAN, 2012)

Já em 1972, Esteve Reich vem a substituir o processo de defasagem gradual de transformação através da sobreposição de dois andamentos ligeiramente diferentes por um mecanismo que se baseia no deslocamento (imediato) de uma figura rítmica. A primeira obra que utiliza esse deslocamento imediato é Clapping Music (1972). Assim, o deslocamento entre os dois intérpretes é realizado através da subtração de uma das notas ou pausas que compõem a frase musical por um dos intérpretes.

Alguns procedimentos rítmicos não foram criados no século XX, entretanto, seu desenvolvimento e utilização se destacam no repertório desse período. Entre esses procedimentos rítmicos estão:

1. Assimetria: "Termo que se refere à utilização de compassos de numerador ímpar, como 5/8, 11/8, 7/4, que sugerem uma pulsação resultante de proporções irregulares.” (FRIDMAN, 2012).

2. Métricas Combinadas: Utilização de acentuações marcadas em uma mesma fórmula de compasso ou a troca de fórmulas de compasso durante a peça que realizem uma mudança de acentuação (pulsação) da obra.

3. Polirritmia: Utilização de padrões rítmicos diferentes acontecendo simultaneamente. "É bastante frequente a utilização de quiálteras nos procedimentos polirrítmicos, como os encontrados na música africana em geral, podendo haver também uma série de combinações possíveis para este procedimento.” (FRIDMAN, 2012)

4. Polimetria: Trata-se da utilização de fórmulas de compasso diferentes simultaneamente. Cardassi (2008) apresenta a obra For Philip Guston (1984) do compositor norte americano Morton Feldman. Nessa obra "nos primeiros quatro compassos existem quatro fórmulas diferentes de compasso: 3/8, 1/4, 3/16 e 3/32, as quais 
se repetem, em outra ordem, para cada instrumento, gerando uma polimetria." (CARDASSI, 2008). Para a flauta, a ordem é 3/8, 3/32, 3/16 e 1/4; para o vibrafone, $3 / 16,1 / 4,3 / 32$ e $3 / 8$ e, para o piano, $1 / 4,3 / 8,3 / 16$ e $3 / 32$.

5. Politempo: Termo utilizado para descrever músicas em que dois ou mais tempos ocorrem simultaneamente. No mundo ocidental, a prática da música com politempo tem suas raízes na teoria da música de Henry Cowell (1897-1965). As primeiras práticas são de Charles Ives (1874-1954). Um dos exemplos mais clássicos da utilização de tempos diferentes simultâneos é a obra do compositor grego Iannis Xenakis - Persephassa (1969). Escrita para seis percussionistas tocando setups de percussão múltipla, a obra possui uma seção onde cada um dos intérpretes toca em andamentos diferentes: é comum assistirmos performances dessa obra onde os intérpretes utilizam fones de ouvido com os metrônomos para auxiliar na realização desse trecho.

Um dos procedimentos rítmicos mais importantes criados no século XX é a modulação métrica. Segundo Larrick:

Uma das técnicas de compositores modernos é a modulação métrica. Ela ocorre quando um pulso rítmico muda gradualmente através da utilização de um denominador comum de notação. O ritmo pode diminuir ou acelerar. Como na modulação harmônica, a mudança é feita gradualmente - embora às vezes muito rapidamente; o novo ritmo parece "florescer" fora do tempo antigo, de forma que muitas vezes é imperceptível para o ouvinte. Em minha opinião, este aspecto de "camuflagem" é muito eficaz em provocar uma resposta emocional sutil no ouvinte atento de músicas contendo modulação métrica. (LARRICK, 1988, p. 46)

Modulação métrica é um processo rítmico onde ocorre a mudança de um andamento para outro. Entretanto, existe a utilização de um "pivô", ou seja, a mudança é realizada através de uma figura rítmica do primeiro andamento que tem valor equivalente com uma figura do segundo andamento. O compositor norte americano Elliott Carter é considerado como um dos inventores dessa técnica composicional. Carter prefere chamar esse processo de modulação temporal e o definiu como "um procedimento no qual cada tempo constituído de pulsos segue de uma maneira ordenada entre os diferentes compassos" (CARTER, 1997, p. 226).

A técnica de Carter consiste na transição precisa entre andamentos contíguos distintos, através de um valor rítmico pivô que, embora notado por figuras rítmicas distintas em cada um dos andamentos articulados, mantém em ambos uma mesma duração cronométrica. (OLIVEIRA, 2011, p. 3)

Essa técnica composicional foi importante e amplamente utilizada por diversos compositores, pois sua utilização "possibilita aos compositores determinar de maneira mais clara as mudanças de andamento de suas obras e aos intérpretes realizarem estas mudanças de maneira mais precisa.” (PEREIRA e TRALDI, 2010).

O compositor brasileiro Arthur Kampela, durante seu trabalho de doutorado realizado nos EUA, desenvolveu um procedimento rítmico conhecido como modulação micrométrica. Esse procedimento é amplamente utilizado pelo compositor em suas composições durante o período de 1995 e 1999.

A modulação micrométrica é baseada na modulação métrica de Carter com influência da escrita complexa do compositor britânico Brian Ferneyhough e a escola de composição chamada Nova Complexidade do final do século XX. 
Entre os elementos complexos utilizados por Ferneyhough está a utilização de fórmulas de compasso que dividem irregularmente a figura da semibreve. Por exemplo: Um compasso 7/20 será preenchido por sete quintinas de semicolcheia. Segundo Bortz, (2006) "essa notação pode causar ao intérprete não familiarizado uma reação negativa ao que entende como dificuldades excessivas na escrita.” (BORTZ, 2006, p. 86). Assim,

A ideia de modulação micrométrica de Kampela é a de oferecer ao intérprete a chance de se adaptar gradualmente às mudanças de velocidade de uma cadeia de quiálteras a outra. Ao agrupar quiálteras secundárias mantendo a mesma velocidade metronômica de um subgrupo a outro adjacente, Kampela adapta a ideia de Carter a um contexto rítmico mais complexo. (BORTZ, 2006, p. 88)

Segundo o próprio compositor:

"O conceito de continuidade é crucial se queremos desenvolver uma teoria da modulação micrométrica. Para conectar uma figura rítmica (ou uma quiáltera anterior) a uma nova, é necessário que existam velocidades rítmicas equivalentes em ambos os lados das quiálteras aninhadas. Estas propriedades da álgebra são conhecidas como propriedades comutativa e associativa e afirmam que os elementos de uma operação produzirão os mesmos resultados independentemente da ordem de seus fatores." (KAMPELA,1998, p. 6)

De maneira geral a modulação micrométrica realiza o mesmo processo de mudança de andamento realizado pela modulação métrica. A principal diferença é que a modulação métrica é utilizada para realizar mudanças de andamento da obra, enquanto que a modulação micrométrica é utilizada para realizar mudanças de andamentos entre quiálteras aninhadas.

Ao falar sobre procedimentos rítmicos criados e/ou desenvolvidos no século XX não poderíamos deixar de citar a concepção rítmica do compositor inglês Brian Ferneyhough. Segundo Malt (1999¹ , apud KOZU, 2002),

o tempo e o ritmo são concebidos por Ferneyhough de acordo com as seguintes características: Como um espaço discreto e finito (um espaço de durações), formalizado a partir de manipulações simbólicas através de subdivisões e multiplicações discretas das unidades de tempo ("encapsulações"); Os compassos são utilizados enquanto segmentos temporais de diversos tamanhos, como forma de controlar a evolução da densidade dos eventos; Esta noção de 'densidade’ está associada a uma relação entre as subdivisões por unidades de tempo: das quantidades de impulsos discretos num dado espaço-temporal; Os esquemas rítmicos se fundam em certas relações de proporções originadas sob um esquema fundamental por diversas operações combinatórias: permutações, interpolações, incrustações, sobreposições, filtros, etc. (MALT, 1999, apud KOZU, 2002)

A complexidade na obra de Ferneyhough está ligada à sua escrita automática (pensamento serial) somada ao modo complexo com que os articula,

por acumulação e sobreposição de diversos planos ou camadas de séries paralelas, de diversos níveis paramétricos totalmente heterogêneos uns dos outros e que posteriormente são costurados, recortados, reassociados e recombinados de acordo com critérios formais ou informais, onde qualquer ponto dos planos, das séries, conectam-se a qualquer outros pontos de qualquer outra série, sem se remeter a um único ponto de origem. (KOZU, 2002, p. 56)

Apesar da escrita complexa de Ferneyhough não se tratar de um novo procedimento rítmico, a maneira como é realizado seu processo composicional cria ritmos 
extremamente complexos e de difícil realização. Dessa forma, o elemento rítmico ganha importância dentro dessas composições e são elementos fundamentais do processo composicional.

No século XX também ocorre uma ampla exploração de escrita gráfica e de ritmos indeterminados. Antunes (1989) apresenta uma série de notações utilizadas na música contemporânea e, entre elas, várias figuras que não possuem uma determinação exata, como acelerando e desacelerando gradativamente, notações proporcionais, notações que indicam a duração em segundos, etc.

Essas escritas indeterminadas e os processos rítmicos aqui apresentados trazem novos desafios e responsabilidades para os intérpretes do século XXI. Assim, é extremamente importante o estudo e conhecimento desses procedimentos. A seguir, apresentaremos algumas experiências de estudo e performance desses elementos com a utilização de dispositivos eletrônicos.

\section{Estudo e Performance de Modulações Métricas}

O processo de modulação métrica criado por Carter foi estudado dentro da pesquisa através da análise e performance da obra para tímpanos solo Canaries (1949) do próprio compositor Elliott Carter. Nessa obra, o compositor explora amplamente a técnica de modulação métrica. Segundo o consagrado percussionista norte americano Jan Willians, revisor da obra para Carter:

Não há melhor exemplo de modulação métrica do que os 25 primeiros compassos dessa peça (Canaries). Tenho em muitas ocasiões utilizado esse trecho para demonstrar como funciona a modulação métrica ou demonstrar como pode ser utilizada pelos compositores. O ciclo completo de tempos nesses 25 compassos, iniciando em semínima pontuada $=90$ e regressando a esse tempo no compasso 25 é nada menos que brilhante. (WILLIANS 2000, p. 14)

Após o estudo e análise de todas as modulações métricas presentes na obra foi desenvolvido no computador, através do software Pure Data, um metrônomo que realiza todas as modulações da obra apresentando dois pulsos simultâneos nos momentos de preparação e conclusão das modulações métricas. Além disso, o metrônomo possibilita ao percussionista estudar as obras em andamentos mais lentos. Ao alterar o andamento inicial da obra, a programação realizada calcula as mudanças de andamento necessárias em todas as modulações métricas da obra.

O estudo da obra foi realizado por um aluno de iniciação científica e foi constatado que a utilização do metrônomo desenvolvido foi extremamente importante para a compreensão dos processos de modulação métrica pelo intérprete, além de terem auxiliado na obtenção de uma maior precisão na realização das modulações presentes na obra. A descrição da programação realizada em Pure Data está descrita no artigo "Modulação Métrica na Obra Canaries de Elliott Carter" (PEREIRA e TRALDI, 2010).

\section{Phase-shifting}

O processo de phase-shifting, criado por Steve Reich, foi pesquisado e explorado com a utilização do computador de duas maneiras na pesquisa aqui descrita: 
1) Estudo de uma obra acústica do compositor com utilização da tecnologia para auxiliar na preparação da performance, e

2) Criação de uma obra onde fosse possível a realização do processo de phase-shifting entre um intérprete humano e o computador.

Para o primeiro estudo, a obra escolhida foi Piano Phase. Novamente uma programação no software Pure Data foi realizada para auxiliar os dois intérpretes a melhor compreenderem o processo de mudança de fase e proporcionar uma execução com maior precisão dos momentos de coexistência de dois andamentos distintos.

A programação realizada possibilitou aos intérpretes ouvir, em andamentos diversos, o processo de defasagem ocorrendo entre as duas vozes. Além disso, o programa calcula qual deve ser a variação de andamento que o intérprete que irá realizar o deslocamento deve realizar. Em momento algum o objetivo da pesquisa foi o de fazer com que os intérpretes realizassem o processo de deslocamento matematicamente perfeito como é realizado pelo computador. Entretanto, a audição dessa precisão do computador e o estudo junto com o áudio foram ferramentas que auxiliaram os intérpretes a adquirirem maior controle do processo de mudança de fase durante a performance. A programação realizada está descrita no artigo "Estratégias de Estudo e Performance do Processo de Phase-Shifting utilizado por Steve Reich na obra Piano Phase” (CAMPOS, TRALDI e MANZOLLI, 2011).

Para a segunda etapa da pesquisa, o objetivo foi compor uma obra que possibilitasse a realização de phase-shifting tendo como um dos intérpretes o computador. A obra criada, Namíbia (2012), foi escrita para instrumento livre e computador. Assim, é possível realizar a obras com diversos instrumentos.

Em todos os processos de phase-shifting estudados, o deslocamento temporal era realizado por um dos intérpretes através de um acelerando ou de uma mudança súbita (subtração de notas ou pausas). Para possibilitar a realização do processo com o computador foi necessária uma pequena modificação. O intérprete humano manterá o andamento enquanto os deslocamentos serão realizados pelo computador através de um atraso e não aceleração da frase musical.

O processo de composição e desenvolvimento da programação está descrito no artigo "O processo de pashe-shifting criado por Steve Reich em obra para percussão e eletrônicos em tempo real” (TRALDI, 2012). A performance dessa obra já foi realizada diversas vezes e o resultado alcançado está totalmente de acordo com os objetivos da pesquisa.

\section{Reflexões e conclusões}

A criação musical do século XX foi extremamente rica e trouxe novos desafios interpretativos para os instrumentistas. Entretanto, para poder lidar com essas novas linguagens e técnicas composicionais são necessários intérpretes extremamente versáteis, que se adaptem rapidamente a diferentes contextos musicais. Os procedimentos rítmicos criados e/ou desenvolvidos no século XX, tratados nesse texto, são exemplos de técnicas composicionais que exigem estudo e preparação dos intérpretes.

A pesquisa aqui apresentada e desenvolvida na Universidade Federal de Uberlândia busca utilizar dispositivos eletrônicos, principalmente o computador, para auxiliar intérpretes no estudo e compreensão desses processos musicais. As experiências realizadas demonstraram que a utilização de programas de computador pode auxiliar na rápida compreensão e maior precisão na realização desses processos rítmicos estudados. 
Outro objetivo da pesquisa é o de criar obras musicais para interação entre homem e máquina que explorem esses processos rítmicos do século XX. Como resultado dessa pesquisa, foi criada a obra Namíbia, que possibilita a realização de phase-shifting entre um intérprete e o computador.

O rápido desenvolvimento e popularização dos computadores fazem com que eles sejam ferramentas extremamente importantes para diversos aspectos de nossas vidas. Essa pesquisa tem utilizado o computador com o objetivo de criação e performance musical, mas também como ferramenta de auxílio na compreensão e performance de processos musicais em obras sem interação com dispositivos eletrônicos. Os resultados alcançados são extremamente positivos e demonstram que o computador pode ser um ótimo instrumento de auxílio na preparação de intérpretes.

\section{Nota}

1 Malt, Mikhaïl (1999). "Brian Ferneyhough et l'aide informatique à l'ècriture”. In: P. Szendy (Ed.), Brian Ferneyhough. Paris: L’Harmattan.

\section{Referências}

ANTUNES, Jorge. Notação na música contemporânea. Brasília: Sistrum, 1989.

BORTZ, Graziela. Modulação micrométrica na música de Arthur Kampela. Per Musi, Belo Horizonte, n.13, 2006, p. 85-99

CAMPOS, Cleber; TRALDI, Cesar; MANZOLLI, Jônatas. Estratégias de Estudo e Performance do Processo de Phase-Shifting utilizado por Steve Reich na obra "Piano Phase". In: XXI ANPPOM, 2011, Uberlândia: Editora da ANPPOM, 2011.

CARDASSI, Luciane. For Philip Guston de Morton Feldman: Ensaios e Performance - ou como sobreviver a quatro horas de música. Música Hodie, V.8 Número 01, 2008.

CARTER, Elliott. The Time Dimension in Music. In: Jonathan W. Bernard (Editor). Collected Essays and Lectures 1937-1995. Rochester: University of Rochester Press, 1997. p. 226.

FRIDMAN, Ana Luisa. Conversas com a música não ocidental: da composição do século XX para a formação do músico da atualidade. DAPesquisa - Revista do Centro de Artes da UDESC, 2012: p. 355-371.

KAMPELA, Arthur. "Micro-Metric Modulation: New Directions in the Theory of Complex Rhythms". Tese de doutorado, Columbia University, 1998.

KOZU, Fernando. "A complexidade, a figura e o ritmo no pensamento composicional de Brian Ferneyhough”. In: Anais do V Fórum CLM 2002. São Paulo: ECA/USP, 2002. p. 45-57.

LARRICK, Geary. "Symphonic Percussion: Metric Modulation”. Percussive Notes, The journal of the Pecussive Arts Society, v.27, n.1, 1988, p. 46-49.

LESAGE, Felipe. O ritmo nas obras "Piano Phase" e "Drummings", de Steve Reich. 2011.

OLIVEIRA, Francisco. Modulação Métrica em Fantasia, do Quarteto de Cordas No. 1 de Elliott Carter. TCC, IARTE, Unicamp, Campinas-SP, 2011. 
PEREIRA, Lúcio; TRALDI, Cesar. Modulação Métrica na Obra Canaries de Elliott Carter. In: XX Congresso da ANPPOM, 2010, Florianópolis. Anais do XX Congresso da ANPPOM. Florianópolis: Editora da Udesc, 2010.

REICH, Steve. Steve Reich: Music as a Gradual Process, Part. II. Autumn: Perspectives of New Music, v.20, 1981, p. 225-286.

TRALDI, Cesar. O processo de pashe-shifting criado por Steve Reich em obra para percussão e eletrônicos em tempo real. In: 8 Simpósio de Cognição Musical, 2012, Florianópolis. Anais SIMCAM 8. Florianópolis: Editora da Udesc, 2012.

WILLIANS, Jan. “Elliott Carter's 'Eight Pieces for Timpani’ - The 1966 Revisions”. Percussive Notes, The journal of the Pecussive Arts Society, v.38, n.6, 2000, p. 8-17.

Cesar Adriano Traldi - Bacharel em percussão pela Unicamp, posteriormente, sob a orientação do Prof. Dr. Jônatas Manzolli realizou, na mesma instituição, sua pesquisa de mestrado focada no estudo do processo interacional do intérprete com meios tecnológicos e pesquisa de doutorado sobre linguagem contemporânea para percussão e dispositivos eletrônicos em tempo real. É pesquisador do Núcleo de Música e Tecnologia e professor de percussão da UFU. 